\title{
Blood Coagulation Changes Following Hypoxemia in the Near-Term Fetal Lamb
}

\author{
C. THOMAS KISKER, ${ }^{(30)}$ JEAN E. ROBILLARD, AND WILLIAM R. CLARKE \\ Department of Pediatrics and Preventive Medicine, University of Iowa College of Medicine, Iowa City, Iowa USA
}

\begin{abstract}
Summary
The effects of severe hypoxemia on blood coagulation factor activities and other physiologic parameters were examined in ten near-term chronically catheterized fetal lambs (135-140 days gestation). Six lambs were subjected to a mean $\mathrm{Po}_{2}$ of $13.8 \pm 1.4$ mmHg for $60 \mathrm{~min}$. The other four served as controls. Before, during and after hypoxemia, the white blood cell count, hemoglobin, hematocrit, platelet count, $\mathrm{pH}, \mathrm{PCO}_{2}, \mathbf{P o}_{2}$, mean arterial pressure, heart rate, norepinephrine and epinephrine were measured. Measures of coagulation factor activities including platelet counts, partial thromboplastin times, prothrombin times and quantitation of plasma activities for factors I, II, V, VII, VIII, IX, X, XI, XII, fibrin degradation products (FDP), antithrombin III, fibrin monomer and ristocetin cofactor activity were also done. An increase in mean arterial pressure from $48 \pm 2 \mathrm{mmHg}$ to $56 \pm 2$ $\mathrm{mmHg}$, and an increase in epinephrine from $22 \pm 9 \mathrm{pg} / \mathrm{dl}$ to 419 $\pm 199 \mathrm{pg} / \mathrm{dl}$, and norepinephrine from $431 \pm 98 \mathrm{pg} / \mathrm{dl}$ to $2408 \pm$ $868 \mathrm{pg} / \mathrm{dl}$ occurred in the hypoxemic animals. There was also a slight decrease in the pH from $7.37 \pm 0.01$ to $7.32 \pm 0.03$ in the hypoxemic animals. The only significant change in blood coagulation factors during hypoxemia was a slight increase in fibrin monomer from $5.6 \pm 0.8 \mu \mathrm{g} / \mathrm{ml}$ to $12.6 \pm 2.0 \mu \mathrm{g} / \mathrm{ml}$. After the experiment, the animals were allowed to go to term and deliver spontaneously. Delivery occurred from 2-12 days after the experiment (mean 6 days). Blood coagulation factor activities I, II, V, VII, VIII, IX, X, XI, XII, antithrombin III, fibrin monomer, and fibrin degradation products were measured after delivery in the hypoxemic and control animals. Except for factor XII, values obtained from ten previously catheterized control fetal lambs after spontaneous delivery did not differ from the current control animals after delivery.

Values on postdelivery samples for the two control groups were therefore pooled for analysis. Factors VIII, and IX were found to show increased activity during the 2 wk after delivery in hypoxemic animals when compared with controls. In contrast, the values for factors II, V, VII, $X$ and fibrinogen showed lower activity in hypoxemic as compared to control animals during the early neonatal period. The study demonstrates that though there are no severe acute effects on blood coagulation during severe hypoxemia in the near-term fetus except perhaps transient low-grade disseminated intravascular coagulation, the episode of hypoxemia appears to alter the future development of blood coagulation factor activities during the early neonatal period.
\end{abstract}

\section{Speculation}

Hypoxemia in the near-term fetus delays the normal development of prothrombin, factors $\mathrm{V}$, VII, $\mathrm{X}$, and fibrinogen during the early neonatal period and accelerates the development of factors VIII and IX. The differences in factor responses may help explain the variable results reported in human infants. The results also suggest that both thrombotic and hemorrhagic tendencies might be a consequence of prenatal hypoxemia.

Hypoxemia in the newborn infant following delivery has been associated with various abnormalities of blood coagulation $(1,2$,
$5,9,16,18,25,29)$. Some authors report changes consistent with intravascular coagulation (5) whereas others suggest changes related to decreased synthesis of clotting factors by the liver $(2,16)$. When hypoxemia occurs before delivery, still other authors suggest an acceleration of the maturation of blood coagulation factor activities $(1,27)$. Previous studies in our laboratory demonstrated that hypoxemia when induced early in the third trimester of pregnancy in the chronically catheterized fetal lamb did not result in major changes in blood coagulation factor activities. The current study examines the effects of an identical episode of hypoxemia on near-term chronically catheterized fetal lambs. As in the previous study of early gestation lambs, the abnormalities usually associated with hypoxemia including acidosis, hypotension and hypercarbia were minimal, allowing examination of the effects of a relatively pure state of hypoxemia.

\section{MATERIALS AND METHODS}

Pregnant mixed Dorset-Suffolk ewes were obtained from existing sources and were housed throughout the study at the University of Iowa Animal Quarters.

The gestational ages of the fetuses were known based upon induced ovulation techniques (10). Before surgery the animals were fasted for $48 \mathrm{~h}$. Anesthesia of the ewe and surgery on the fetus were performed as described previously $(14,24)$. During the acute studies, the ewes with their chronically catheterized fetuses were transferred into small carts restricting them to upright position. Six of the chronically catheterized fetuses were exposed to hypoxemia. Four of the chronically catheterized fetal lambs served as concurrent controls.

Blood samples were obtained from the fetuses via the chronic catheters before the onset of hypoxemia. After removing an initial $1 \mathrm{ml}$ of blood to clear the line of saline, a sample of blood totaling $9 \mathrm{ml}$ was obtained for the various measurements to be described. After the initial $9 \mathrm{ml}$ collection of blood, hypoxemia was induced in the six fetal lambs by placing a bag over the ewe's head and having her breathe a mixture of $11.1 \%$ oxygen balanced with nitrogen. The oxygen-nitrogen gas mixture was precalibrated with an accuracy level of $\pm 0.11 \%$ by Airproducts Company of Pennsylvania. At $30 \mathrm{~min}$ into hypoxemia, a second $9-\mathrm{ml}$ blood sample was obtained from both hypoxemic and control fetuses. Hypoxemia was concluded after a total of $60 \mathrm{~min}$ by removing the bag and having the ewe breathe room air. Prolonging the hypoxemic episode beyond 60 min always resulted in acidosis and occasionally hypotension and death to the fetus. These events would preclude spontaneous delivery of live born animals and our ability to examine the effects of hypoxemia on coagulation factor activities postnatally. For this reason the 60 -min hypoxemic episode was used.

Third and fourth samples of blood totaling $9 \mathrm{ml}$ each were obtained from the fetal lambs $30 \mathrm{~min}$ and $2 \frac{1}{2} \mathrm{~h}$ from the completion of the hypoxemic stress. The animals were then returned to their permanent quarters. During the acute studies, $0.5 \mathrm{ml}$ of blood was collected anaerobically in heparinized plastic syringes and measurements of $\mathrm{pH}, \mathrm{PCO}_{2}$, and $\mathrm{PO}_{2}$ were immediately determined with the appropriate $\mathrm{pH}, \mathrm{PCO}_{2}$, and $\mathrm{Po}_{2}$ electrodes at $39^{\circ} \mathrm{C}$ using a radiometer pH amp 72 NK2 acid base analyzer (Radi- 
ometer Company, Denmark). Protein content of fetal serum was determined on $0.5 \mathrm{ml}$ of clotted blood using a refractometer (Medical Instruments Company, Baltimore, MD). Hemoglobin, hematocrit, and white blood cell counts were measured using a Coulter Model S on a $0.5 \mathrm{ml}$ aliquot of blood that was anticoagulated with EDTA. Platelet counts were also obtained on this aliquot using phase microscopy. Epinephrine and norepinephrine were determined on a $2 \mathrm{ml}$ aliquot collected in $40 \mu \mathrm{l}$ of anticoagulant containing $90 \mathrm{mg} / \mathrm{ml}$ EDTA, $60 \mathrm{mg} / \mathrm{ml}$ glutathione. A radioenzymatic assay (CAT-A-KIT, Upjohn Company, Kalamazoo, MI) as previously described by Passon and Peuler (21) was used for the epinephrine and norephrine determinations.

Coagulation factor activities were measured on plasma from 2.7 $\mathrm{ml}$ aliquots of blood anticoagulated with $0.3 \mathrm{ml}$ of $0.05 \mathrm{M}$ sodium citrate, $\mathrm{pH}$ 5.0. Standard techniques for measuring the prothrombin times (28) and partial thromboplastin times (23) were used. Specific factor activities II, V, VII, VIII, IX, X, XI, and XII were measured using one-stage assays measuring the ability of the test plasma to correct plasma known to be deficient in the factor to be tested (20). Human deficient plasmas were used and an adult sheep standard pool consisting of plasma from ten nonpregnant ewes was used for calibration. Fibrinogen concentration was measured as clottable protein (6). Von Willebrand factor activity was measured using washed formalin fixed frozen platelets according to the method of Brinkhous and Read (3). Antithrombin III was measured in plasma using the synthetic substrate $M$ tosyl-gly-proarg- $p$-nitroanilide as described by Leff, et al. (15). All activities are quoted as \% of the reference standard pool of sheep plasma obtained from ten nonpregnant ewes. Plasmin digestion products of fibrinogen/fibrin were measured in serum from a $0.5 \mathrm{ml}$ aliquot of blood allowed to clot in $5 \mu$ l of a solution of $0.05 \mathrm{M}$ EACA, $0.125 \mathrm{M} \mathrm{CaCl}_{2}, 10 \mathrm{U} / \mathrm{ml}$ thrombin. The method of Merskey and co-workers (17) using rabbit anti-sheep fibrinogen antibody and sheep fibrinogen coated red blood cells was used. Fibrin monomer was measured according to the method of Kisker et al. (12) on plasma from $2.7-\mathrm{ml}$ aliquots of blood collected in $0.3 \mathrm{ml}$ of anticoagulant containing $2 \%$ EDTA, $10 \mathrm{mg} / \mathrm{ml}$ soybean trypsin inhibitor, $100 \mathrm{U} / \mathrm{ml}$ heparin $\mathrm{pH}$ 7.4. Sheep fibrinogen and antisheep fibrinogen antibody were used throughout.

Fetal arterial, venous, and amniotic pressures were recorded continuously during the experiments using Stratham P23Db pressure transducers (Stratham Instruments Division, Inc.) and a Beckman R611 recorder. Fetal heart rate was monitored with a cardiotachometer triggered from the fetal arterial pressure pulse.

After the completion of the acute experiments, the fetal lambs were allowed to progress to term and deliver spontaneously. All six hypoxemic animals were delivered spontaneously as were the four control animals. Samples of blood were obtained within the first $48 \mathrm{~h}$ after delivery in all animals and sequential samples were obtained during the first 14 days after birth. One control animal died within $72 \mathrm{~h}$ after delivery from parental abuse (the mother had apparently laid on the lamb and he suffocated). Postdelivery samples were available from ten previously studied chronically catheterized fetal lambs. The results obtained on samples from these animals before delivery were the subject of a previous report (14). The values of coagulation factor activities on these previous controls after delivery were compared with the values obtained on the four concurrent control lambs and the six hypoxemic lambs.

Baseline values before the introduction of hypoxemia were compared in the hypoxemic and control groups using one-way analysis of variance. The changes that occurred during hypoxemia $(30 \mathrm{~min})$ and after hypoxemia ( $30 \mathrm{~min}$ and $2 \frac{1}{2} \mathrm{~h}$ ) were compared in the two groups using a repeated measure analysis of variance. A significant interaction with hypoxemia would be indicated by a difference in the response across time in the hypoxemic group as compared with the control group. If the interaction test is not significant, one can assume any changes occuring with time were parallel in the two groups. If the interaction test was not significant, analysis for parallel changes with time in the two groups was carried out. The Bonferroni method was used to adjust for multiple comparisons (19).

Multiple linear regression was used to compare the patterns of

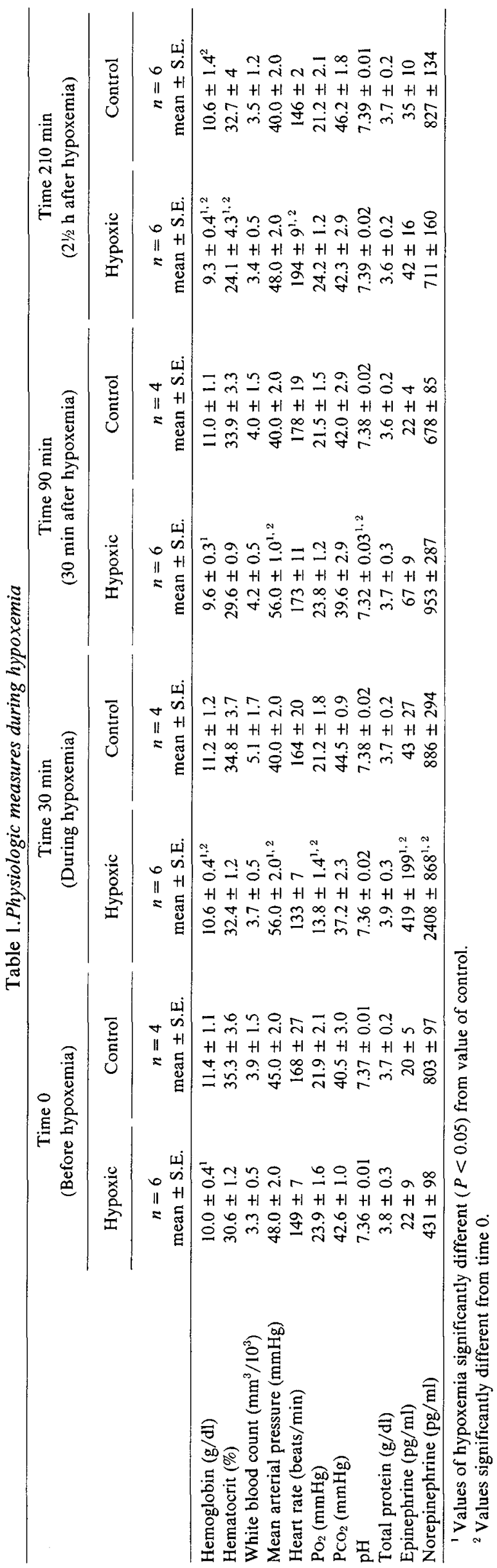


Table 2. Coagulation factor activities during hypoxemia

\begin{tabular}{|c|c|c|c|c|c|c|c|c|}
\hline & \multicolumn{2}{|c|}{$\begin{array}{c}\text { Time } 0 \\
\text { (Before hypoxemia) }\end{array}$} & \multicolumn{2}{|c|}{$\begin{array}{c}\text { Time } 30 \mathrm{~min} \\
\text { (During hypoxemia) }\end{array}$} & \multicolumn{2}{|c|}{$\begin{array}{c}\text { Time } 90 \text { min } \\
\text { (30 min after hypoxemia) }\end{array}$} & \multicolumn{2}{|c|}{$\begin{array}{c}\text { Time } 210 \text { min } \\
\left(2 \frac{1}{2} \mathrm{~h} \text { after hypoxemia) }\right.\end{array}$} \\
\hline & Hypoxic & Control & Hypoxic & Control & Hypoxic & Control & Hypoxic & Control \\
\hline & $\begin{array}{c}n=6 \\
\text { mean } \pm \text { S.E. }\end{array}$ & $\begin{array}{c}n=4 \\
\text { mean } \pm \text { S.E. }\end{array}$ & $\begin{array}{c}n=6 \\
\text { mean } \pm \text { S.E. }\end{array}$ & $\begin{array}{c}n=4 \\
\text { mean } \pm \text { S.E. }\end{array}$ & $\begin{array}{c}n=6 \\
\text { mean } \pm \text { S.E. }\end{array}$ & $\begin{array}{c}n=4 \\
\text { mean } \pm \text { S.E. }\end{array}$ & $\begin{array}{c}n=6 \\
\text { mean } \pm \text { S.E. }\end{array}$ & $\begin{array}{c}n=4 \\
\text { mean } \pm \text { S.E. }\end{array}$ \\
\hline Platelets $\left(\mathrm{mm}^{3} / 10^{3}\right)$ & $530 \pm 82$ & $560 \pm 57$ & $542 \pm 66$ & $532 \pm 54$ & $542 \pm 67$ & $524 \pm 60$ & $516 \pm 53$ & $563 \pm 74$ \\
\hline PT $(\sec )$ & $15.6 \pm 0.7$ & $16.4 \pm 0.8$ & $15.8 \pm 0.7$ & $17.2 \pm 1.1$ & $15.3 \pm 0.6$ & $16.5 \pm 0.6$ & $15.5 \pm 0.7$ & $16.2 \pm 1.0$ \\
\hline PTT (sec) & $49.6 \pm 4.6$ & $46.2 \pm 5.2$ & $49.7 \pm 4.0$ & $49.2 \pm 7.9$ & $47.4 \pm 4.4$ & $47.3 \pm 5.7$ & $47.6 \pm 4.3$ & $46.8 \pm 6.8$ \\
\hline $\mathrm{TT}(\mathrm{sec})$ & $19.7 \pm 1.0$ & $20.2 \pm 2.0$ & $19.5 \pm 1.2$ & $21.5 \pm 2.4$ & $18.6 \pm 1.1$ & $20.4 \pm 1.8$ & $19.2 \pm 0.9$ & $20.8 \pm 1.7$ \\
\hline Fibrinogen ( $\%$ of adults) & $54.4 \pm 6.0$ & $53.1 \pm 9.0$ & $55.1 \pm 7.0$ & $44.0 \pm 7.6$ & $54.5 \pm 5.3$ & $51.1 \pm 8.0$ & $54.6 \pm 5.6$ & $49.9 \pm 8.2$ \\
\hline II activity (\% of adults) & $37.5 \pm 4.9$ & $42.7 \pm 9.1$ & $40.8 \pm 2.2$ & $48.7 \pm 8.6$ & $37.0 \pm 2.6$ & $41.5 \pm 9.3$ & $41.5 \pm 3.8$ & $42.0 \pm 7.8$ \\
\hline $\mathrm{V}$ activity (\% of adults) & $89.0 \pm 11.3$ & $80.0 \pm 12.6$ & $85.8 \pm 9.0$ & $89.6 \pm 20.4$ & $88.5 \pm 9.5$ & $75.5 \pm 11.5$ & $86.0 \pm 8.2$ & $76.3 \pm 13.8$ \\
\hline VII activity (\% of adults) & $65.3 \pm 8.8$ & $50.0 \pm 4.2$ & $65.5 \pm 10.8$ & $53.0 \pm 7.0$ & $63.8 \pm 9.9$ & $54.5 \pm 6.3$ & $60.3 \pm 5.7$ & $57.8 \pm 8.8$ \\
\hline VIII activity ( $\%$ of adults) & $53.8 \pm 9.9$ & $42.8 \pm 3.8$ & $57.5 \pm 11.9$ & $42.7 \pm 4.4$ & $66.8 \pm 15.9$ & $43.5 \pm 3.9$ & $68.0 \pm 16.6$ & $43.5 \pm 5.3$ \\
\hline IX activity (\% of adults) & $42.0 \pm 6.0$ & $40.8 \pm 10.7$ & $45.8 \pm 9.3$ & $37.0 \pm 11.5$ & $44.2 \pm 8.2$ & $41.5 \pm 8.3$ & $50.5 \pm 9.7$ & $44.5 \pm 9.7$ \\
\hline $\mathrm{X}$ activity (\% of adults) & $52.8 \pm 7.3$ & $38.3 \pm 7.2$ & $50.3 \pm 7.8$ & $44.6 \pm 5.2$ & $47.5 \pm 6.7$ & $41.3 \pm 9.2$ & $51.2 \pm 8.0$ & $40.0 \pm 8.6$ \\
\hline XI activity (\% of adults) & $40.2 \pm 12.0$ & $42.5 \pm 10.3$ & $41.3 \pm 10.7$ & $36.3 \pm 9.3$ & $47.7 \pm 16.9$ & $34.2 \pm 8.4$ & $47.6 \pm 18.5$ & $42.5 \pm 8.1$ \\
\hline XII activity (\% of adults) & $36.3 \pm 5.6$ & $40.0 \pm 9.5$ & $41.7 \pm 7.9$ & $38.0 \pm 6.0$ & $39.8 \pm 5.2$ & $49.0 \pm 13.2$ & $43.0 \pm 7.4$ & $46.2 \pm 7.2$ \\
\hline $\mathrm{FDP}(\mu \mathrm{gm} / \mathrm{ml})$ & $0.8 \pm 0.1$ & $0.7 \pm 0.3$ & $0.9 \pm 0.1$ & $0.8 \pm 0.2$ & $0.7 \pm 0.1$ & $1.1 \pm 0.4$ & $2.6 \pm 1.7$ & $0.9 \pm 0.2$ \\
\hline $\begin{array}{l}\text { Von Willebrand activity } \\
\text { (\% of adults) }\end{array}$ & $40.5 \pm 4.3$ & $35.7 \pm 5.3$ & $38.8 \pm 4.4$ & $26.6 \pm 18.2$ & $42.2 \pm 4.8$ & $36.3 \pm 1.4$ & $44.4 \pm 6.6$ & $46.5 \pm 4.1$ \\
\hline Fibrin monomer (\% of adults) & $5.6 \pm 0.8$ & $7.6 \pm 1.4$ & $7.2 \pm 0.5$ & $6.7 \pm 1.6$ & $12.6 \pm 2.0^{1,2}$ & $7.9 \pm 2.3$ & $8.0 \pm 1.4$ & $8.8 \pm 2.6$ \\
\hline Antithrombin III (\% of adults) & $103 \pm 9.3$ & $119 \pm 5.1$ & $98.1 \pm 14.8$ & $124 \pm 5.9$ & $107 \pm 7.3$ & $121 \pm 6.1$ & $101 \pm 5.6$ & $122 \pm 7.8$ \\
\hline
\end{tabular}

'Values of hypoxemia significantly different $(P<0.05)$ from control.

${ }^{2}$ Values significantly different from time 0. 


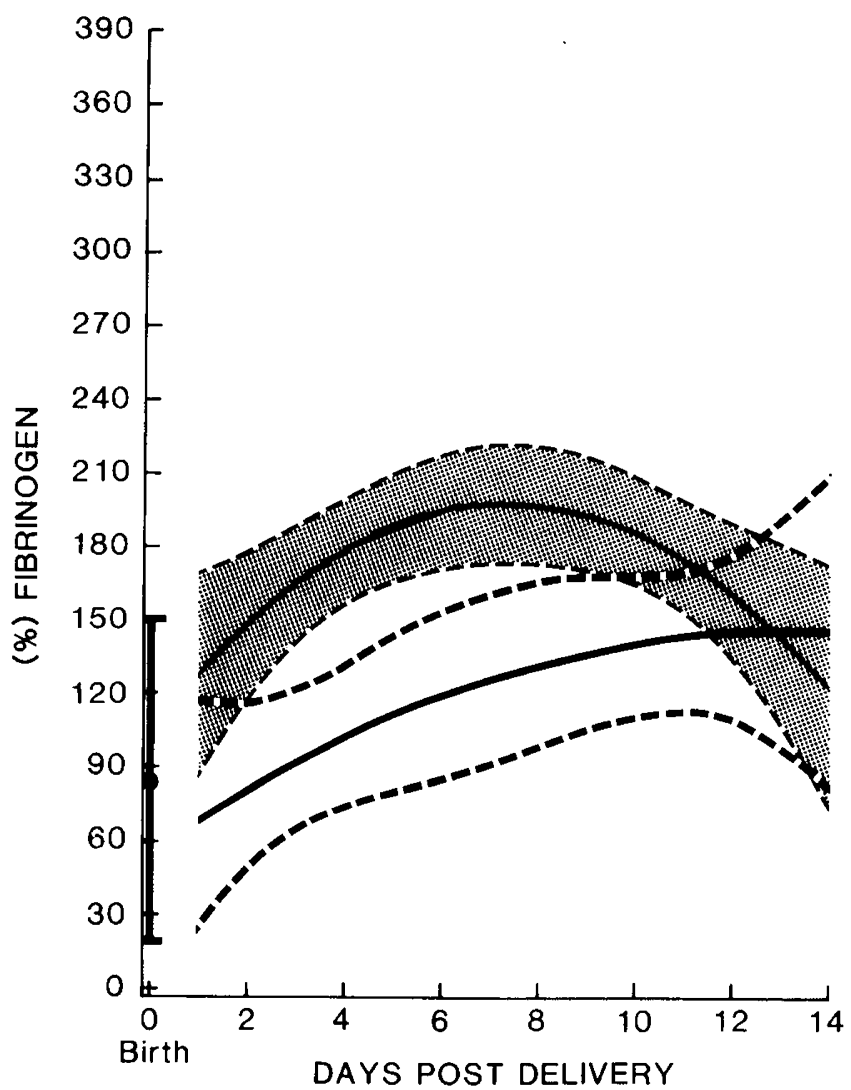

Fig. 1. Fibrinogen. Mean \pm 1 S.D. of values on 14 control animals within $24 \mathrm{~h}$ of delivery indicated as a bar at birth. Thin lines and shaded area indicate regression curve and 95\% confidence limits obtained on samples from 14 control animals during 14 days after birth. Heavy lines and open area indicate regression curve and $95 \%$ confidence limits obtained on samples from six hypoxemic animals during 14 days after birth. Groups are significantly different $(P=0.02)$.

changes in the groups during the 14 days after delivery. Because of the wide variations in values obtained within $24 \mathrm{~h}$ of birth, regression curves were generated on samples obtained $24 \mathrm{~h}$ after delivery and for the subsequent 14 days. There were no differences between the four concurrent and ten previous control animals during the 14 days following delivery except for factor XII which was $24 \%$ lower in the concurrent controls when compared with the previous control animals. Thus except for factor XII, where only concurrent control values are used, comparison of hypoxemic animals with pooled values from both control groups are presented. Preliminary analysis indicated that the patterns of development during the 14 days after delivery were described either by linear or quadric regressions. Both linear and quadric models were therefore used to test for differences in the patterns of change between the control and hypoxemic groups during the first 14 days after delivery.

\section{RESULTS}

Baseline values and values at 30,90 and 210 min during and after hypoxemia are presented in Tables 1 and 2 . There were no significant differences between the control and hypoxemic animals at time zero except that the mean hemoglobin values in the hypoxemic group $(10 \pm 0.4 \mathrm{~g} / \mathrm{dl})$ was significantly lower than the mean value in the control group $(11.4 \pm 1.1 \mathrm{~g} / \mathrm{dl})$. Values obtained on the animals during hypoxemia (30-min samples) and after hypoxemia (90 and $120 \mathrm{~min}$ ) did reveal certain changes. Changes specific to the hypoxemic group included an initial increase in the hemoglobin concentration from $10 \pm 0.4 \mathrm{~g} / \mathrm{dl}$ at time zero to 10.6 $\pm 0.4 \mathrm{~g} / \mathrm{dl}$ at $30 \mathrm{~min}$. There was also an increase, though not statistically significant in the hematocrit from $30.6 \pm 1.2 \%$ to 32.4 $\pm 1.2 \%$. The mean arterial pressure increased from $48 \pm 2 \mathrm{mmHg}$ at time zero to $56 \pm 2 \mathrm{mmHg}$ at $30 \mathrm{~min}$ and continued elevated at the 90 min interval. The $\mathrm{PO}_{2}$ on the hypoxemic group decreased significantly from $23.9 \pm 1.6 \mathrm{mmHg}$ at time zero to $13.8 \pm 1.4$ $\mathrm{mmHg}$ at $30 \mathrm{~min}$ during hypoxemia. A significant increase in the epinephrine and norepinephrine concentrations in the hypoxemic animals was also apparent. Epinephrine increased from a mean of $22 \pm 9 \mathrm{pg} / \mathrm{ml}$ to $419 \pm 199 \mathrm{pg} / \mathrm{ml}$ at $30 \mathrm{~min}$ whereas norepinephrine increased from $431 \pm 98 \mathrm{pg} / \mathrm{ml}$ at time zero to $2408 \pm 868$ $\mathrm{pg} / \mathrm{ml}$ at $30 \mathrm{~min}$. A significant increase in the heart rate was seen at $210 \mathrm{~min}$ in the hypoxemic animals increasing from $149 \pm 7$ beats/min at time zero to $194 \pm 9$ beats $/ \mathrm{min}$ at $210 \mathrm{~min}$. All of these changes were apparent only in the hypoxemic animals and were significantly different from both the baseline values of the hypoxemic animals and from the values obtained in controls. A significant decrease in the hemoglobin concentration was seen in both groups at $210 \mathrm{~min}$. This decrease was no doubt a reflection of the $40 \mathrm{ml}$ of blood withdrawn from the animals during the experimental period. Only one significant change in blood coagulation factors was seen. This change was a significant increase in the fibrin monomer concentration from $5.6 \pm 0.8 \mu \mathrm{g} / \mathrm{ml}$ at time zero to $12.6 \pm 2.0 \mu \mathrm{g} / \mathrm{ml}$ at $90 \mathrm{~min}$ suggesting low-grade intravascular coagulation. The increase in fibrin monomer concentration was minimal and not accompanied by a significant decrease in antithrombin III concentration nor a significant increase in the concentration of the plasmin digestion products of fibrin/fibrinogen (FDP). Though not reaching the level of statistical significance, factor VIII activity did increase from $53.8 \pm 9.9 \%$ at time zero to $68 \pm 16.6 \%$ at $210 \mathrm{~min}$ in the hypoxemic group. Factor IX also increased from $42 \pm 6 \%$ at time zero to $50.5 \pm 9.7 \%$ at 210 $\mathrm{min}$ in the hypoxemic group.

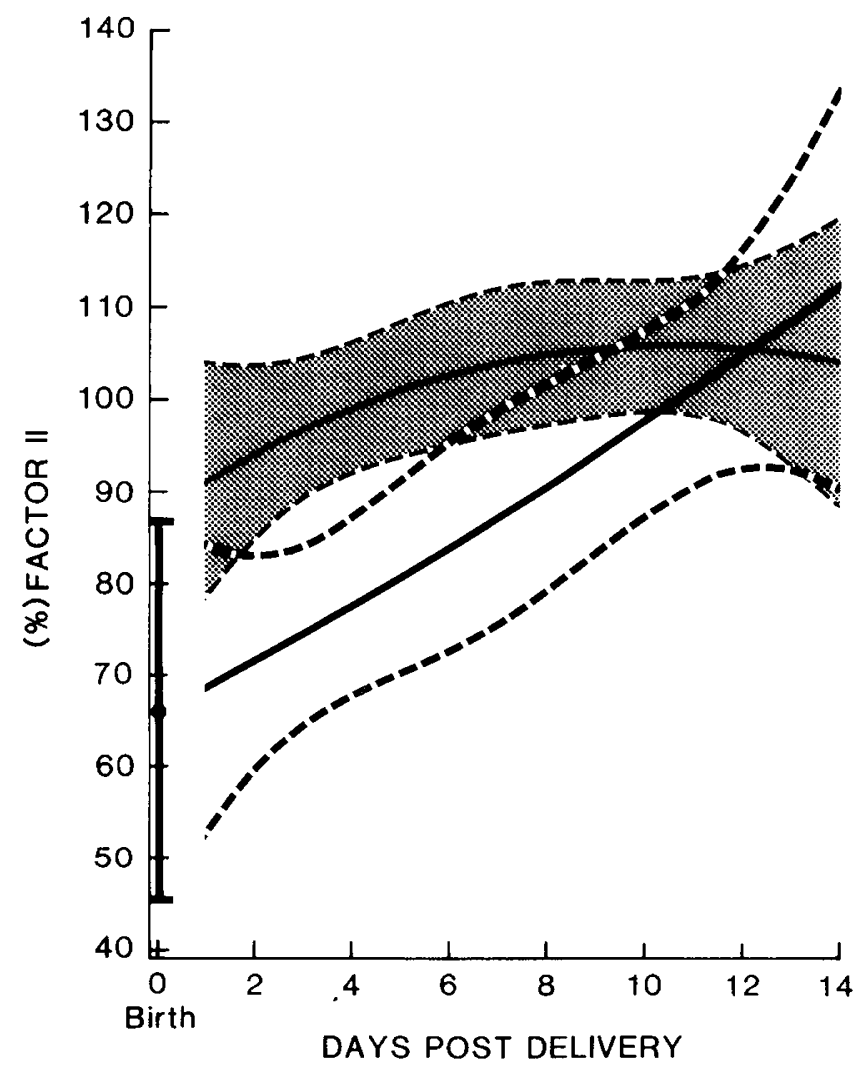

Fig. 2. Prothrombin. Mean \pm 1 S.D. of values on 14 control animals within $24 \mathrm{~h}$ of delivery indicated as a bar at birth. Thin lines and shaded area indicate regression curve and $95 \%$ confidence limits obtained on samples from 14 control animals during 14 days after birth. Heavy lines and open area indicate regression curve and 95\% confidence limits obtained on samples from six hypoxemic animals during 14 days after birth. Groups are significantly different $(P=0.01)$. 
After the experiments all animals were allowed to proceed to term and delivered spontaneously. The hypoxemic animals delivered at $145 \pm 1.6$ days and the control $145 \pm 1.2$ days. The experimental day was $139 \pm 0.9$ days or approximately 6 days before delivery (range of 2-12 days).

Figures 1-9 represent the regression curves for the coagulation factor activities (fibrinogen, factors II, V, VII, VIII, IX, X, XI, $\mathrm{XII}$ ) in the control and hypoxemic animals during the first 14 days after delivery. The mean and S.D. of values obtained within the first $24 \mathrm{~h}$ after delivery in control animals are represented by the bar at time zero. The regression curves begin $24 \mathrm{~h}$ after delivery. The solid line and shaded area are the regression curve for control animals indicating the mean and $95 \%$ confidence limits. The solid line and open area between dashed lines represents the mean and 95\% confidence limits for the experimental group.

Fibrin/fibrinogen degradation products were normal at delivery and throughout the postnatal period and therefore are not plotted. Fibrin monomer levels in control and hypoxemic animals did not differ at birth or during the first $\mathbf{1 4}$ days after delivery. Group differences were also not seen in the postnatal development of factors XI, XII, or antithrombin III.

Significant differences were however apparent in the other clotting factor activities. Fibrinogen, prothrombin, factors VII, and $X$ reached their peak activities approximately 8 days after delivery in control animals. The postnatal development of these factors in the animals who had been exposed to hypoxemia however was significantly delayed but reached control levels by day 14. Factor $\mathrm{V}$ was also significantly lower in hypoxemic

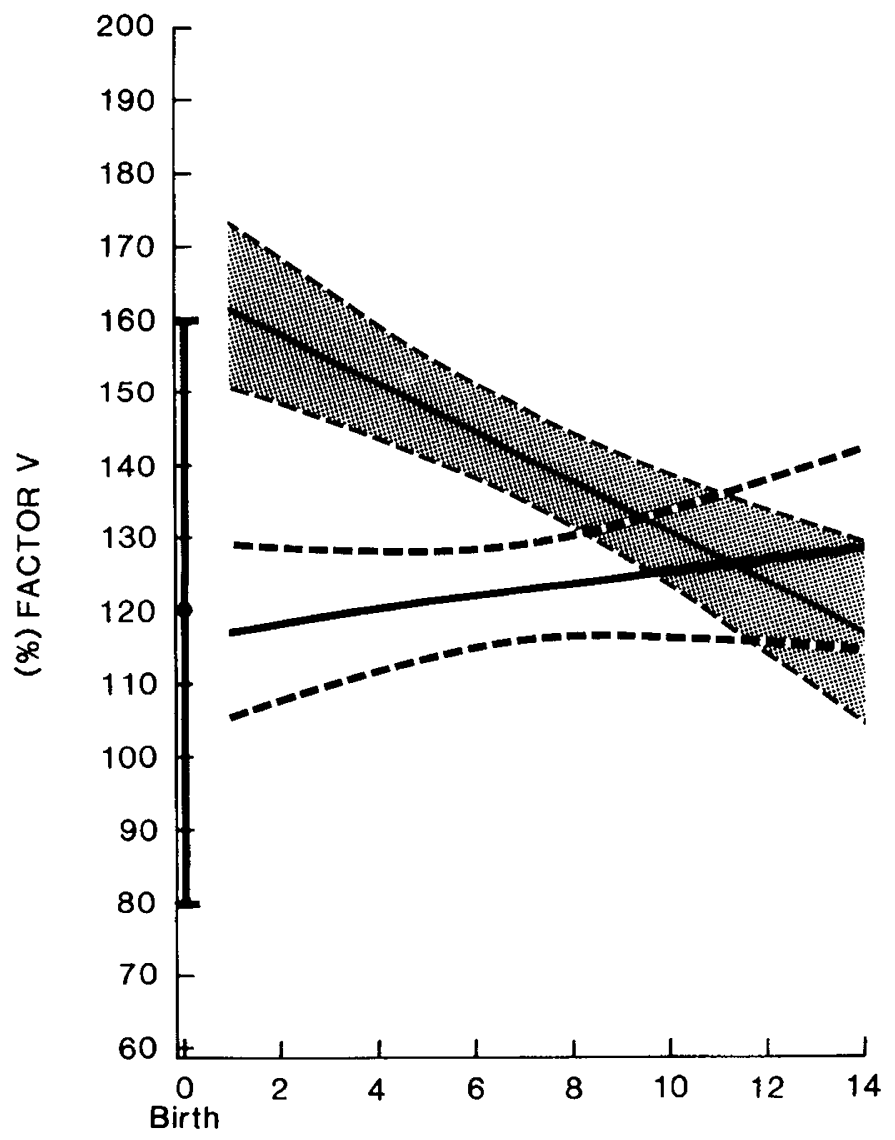

DAYS POST DELIVERY

Fig. 3. Factor V. Mean \pm 1 S.D. of values on 14 control animals within $24 \mathrm{~h}$ of delivery indicated as a bar at birth. Thin lines and shaded area indicate regression curve and $95 \%$ confidence limits obtained on samples from 14 control animals during 14 days after birth. Heavy lines and open area indicate regression curve and 95\% confidence limits obtained on samples from six hypoxemic animals during 14 days after birth. Groups are significantly different $(P=0.01)$.

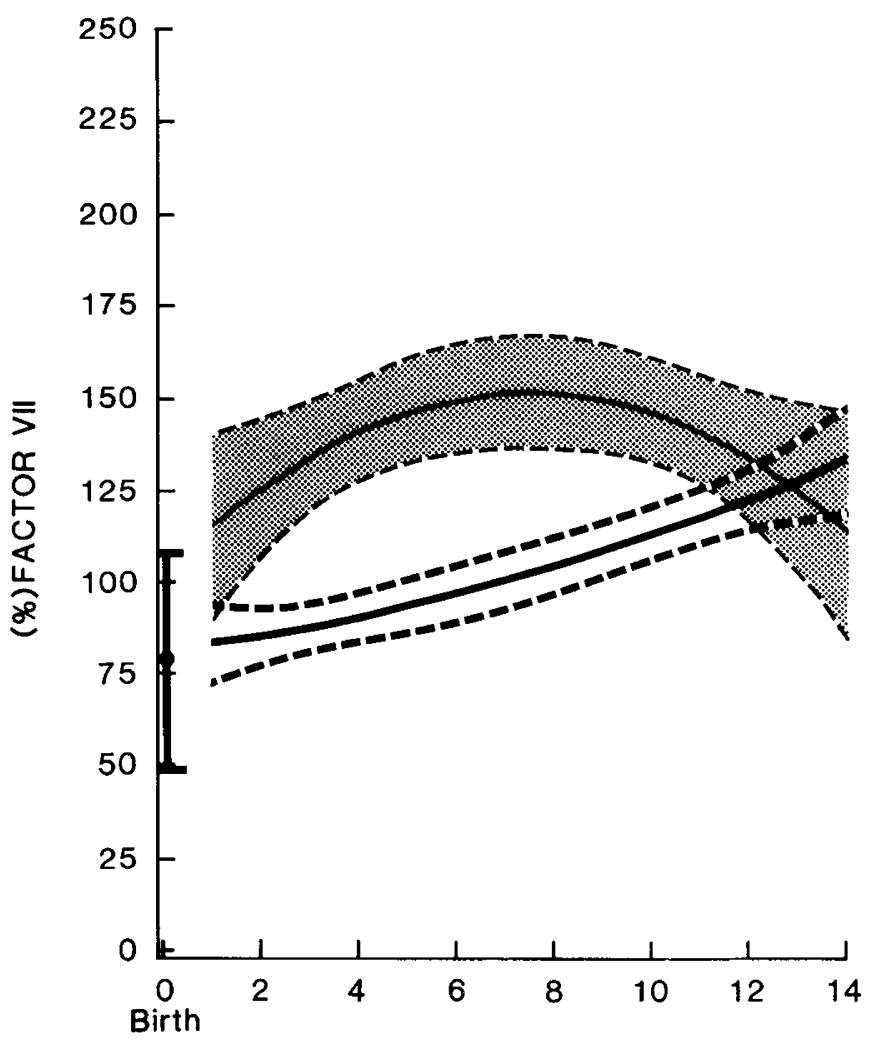

DAYS POST DELIVERY

Fig. 4. Factor VII. Mean \pm 1 S.D. of values on 14 control animals within $24 \mathrm{~h}$ of delivery indicated as a bar at birth. Thin lines and shaded area indicate regression curve and $95 \%$ confidence limits obtained on samples from 14 control animals during 14 days after birth. Heavy lines and open area indicate regression curve and $95 \%$ confidence limits obtained on samples from six hypoxemic animals during 14 days after birth. Groups are significantly different $(P=0.01)$.

animals but also increased during the postnatal period reaching control levels by day 14. In contrast, values for factors VIII were significantly higher in hypoxemic animals throughout the postnatal period and factor IX activity increased in hypoxemic animals during the 14-day period exceeding control levels by the end of the second wk. Because the day of delivery was the same in both groups and the differences were apparent only in the hypoxemic animals, the changes observed appear to be related to the hypoxemic episode induced approximately 6 days before delivery.

\section{DISCUSSION}

Previous studies in our laboratory in which we subjected early third trimester fetal lambs (107-110 days gestation) to severe hypoxemia for $1 \mathrm{~h}$ demonstrated that the lambs tolerated hypoxemia without clinically significant alterations in blood coagulation factor activities (13). During an 18-day follow-up period in these early gestation animals there was no evidence that hypoxemia resulted in any alteration of development except that control animals did increase their levels of factor $\mathrm{X}$ by $10.3 \%$ during the 18-day follow-up; an increase not apparent in the hypoxemic group.

A number of authors have reported significant changes in the blood coagulation factor activities in asphyxiated infants including evidence of decreased synthesis of liver dependent coagulation factor activities $(2,7,8,16)$, disseminated intravascular coagulation $(4,5)$ and even accelerated maturation of blood coagulation $(9,27)$. The variability in the results reported by different authors may reflect variations in the timing and duration of the hypoxemic episode, variation in the maturity of the infants studied, differences in the degree of acidosis, hypercarbia, hypotension and hypother- 
mia that might accompany the hypoxemic stress as well as complex changes resulting from the hypoxemic episode. The chronically catheterized fetal lamb has provided us with a tool whereby it is possible to study the effects of hypoxemia at specific gestational ages unaccompanied by severe acidosis, hypotension, or hypothermia. The current study was undertaken to determine the effects of severe hypoxemia on the near-term fetal lamb (6 days before delivery). The results confirmed expected physiologic changes in the hypoxemic group, including a decrease in $\mathrm{PO}_{2}$ from $23.9 \mathrm{mmHg}$ to $13.8 \mathrm{mmHg}$, and a decrease in $\mathrm{PCO}_{2}$ from 42.6 $\mathrm{mmHg}$ to $37.2 \mathrm{mmHg}$. Hypoxemia also resulted in a significant release of catecholamines. Epinephrine increased from $22 \mathrm{pg} / \mathrm{ml}$ before hypoxemia to $419 \mathrm{pg} / \mathrm{ml}$ during hypoxemia whereas norepinephrine increased from $410 \mathrm{pg} / \mathrm{ml}$ before hypoxemia to 2408 $\mathrm{pg} / \mathrm{ml}$. The increases in catecholamines were reflected by increases in the mean arterial pressure from $48 \mathrm{mmHg}$ to $56 \mathrm{mmHg}$. The changes in the white blood cell count, factor VIII activity, and risocetin cofactor activity were not significant, which confirms the decrease response to catecholamines originally reported by Spirer and colleagues (26) in preterm infants. Though still within physiologic range, there was a slight decrease in $\mathrm{pH}$ from 7.36 to 7.32 in the hypoxemic animals. Initially, there was a slight increase in the hemoglobin concentration in the hypoxemic group. An overall decrease in hemoglobin was however apparent in both hypoxemic and control groups at the end of the experimental period undoubtedly due to the phlebotomy approximating $40 \mathrm{cc}$.

Minimal changes in coagulation factor activities were apparent during the acute hypoxemic episode. Fibrin monomer increased

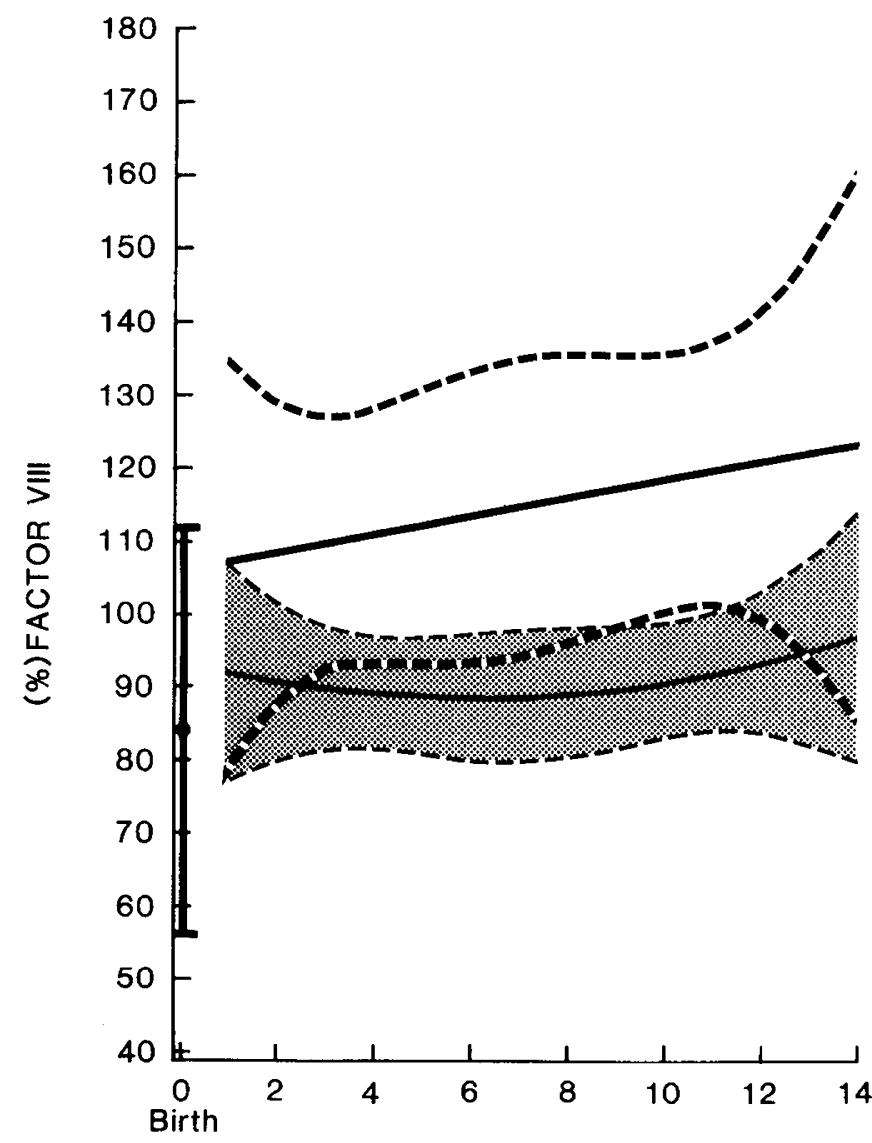

\section{DAYS POST RECOVERY}

Fig. 5. Factor VIII. Mean \pm 1 S.D. of values on 14 control animals within $24 \mathrm{~h}$ of delivery indicated as a bar at birth. Thin lines and shaded area indicate regression curve and $95 \%$ confidence limits obtained on samples from 14 control animals during 14 days after birth. Heavy lines and open area indicate regression curve and $95 \%$ confidence limits obtained on samples from six hypoxemic animals during 14 days after birth. Groups are significantly different $(P=0.01)$.

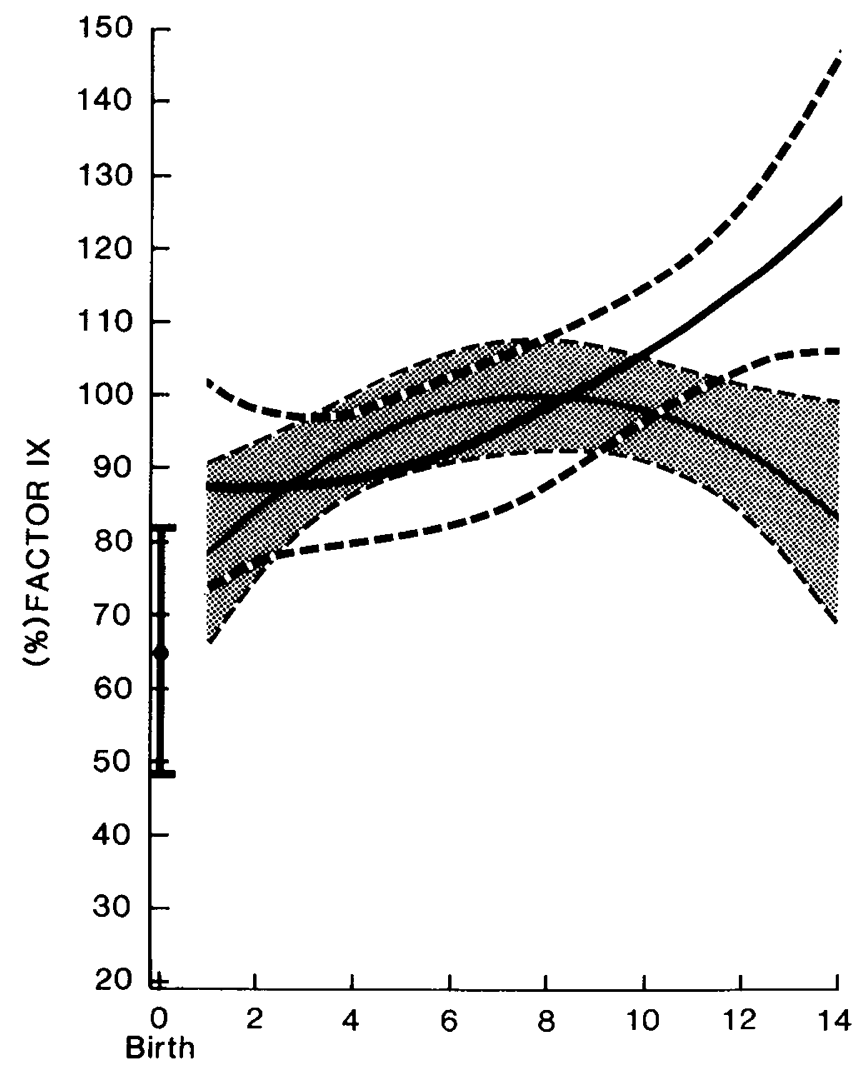

DAYS POST DELIVERY

Fig. 6. Factor IX. Mean \pm 1 S.D. of values on 14 control animals within $24 \mathrm{~h}$ of delivery indicated as a bar at birth. Thin lines and shaded area indicate regression curve and $95 \%$ confidence limits obtained on samples from 14 control animals during 14 days after birth. Heavy lines and open area indicate regression curve and $95 \%$ confidence limits obtained on samples from six hypoxemic animals during 14 days after birth. Groups are significantly different $(P=0.01)$.

from $5.6 \mu \mathrm{g} / \mathrm{ml}$ at time zero to $12.6 \mu \mathrm{g} / \mathrm{ml}$ at $90 \mathrm{~min}$ (30 min after hypoxemia). This was a significant though minimal change both from baseline values and from control values and is suggestive of low-grade disseminated intravascular coagulation. There were however, no significant changes in antithrombin III nor was there the appearance of fibrin degradation products in the plasma to confirm disseminated intravascular coagulation. Overall the nearterm fetal lamb is relatively resistant to the acute effects of severe hypoxemia, though demonstrating more response to catecholamines (increased mean arterial pressure, increased heart rate) than the early third trimester fetuses.

In contrast to minimal acute changes, significant changes were seen in the first 14 days after delivery. The development of fibrinogen, factors II, VII, and X were significantly delayed during the early neonatal period in the hypoxemic animals. The delays were significant $(P=0.02$ for fibrinogen, $P=0.01$ for factor II, $P=0.01$ for factor VII, and $P=0.01$ for factor X; see Figs. 1, 2, $4,7)$. Peak levels of activity in the control animals were reached approximately 8 days after delivery whereas the hypoxemic group did not reach control levels until day 14. Factor $\mathrm{V}$ activity in hypoxemic animals was lower than in controls on day 1 and appeared to gradually rise during the early neonatal period whereas levels on control animals decreased during the 14 day period (Fig. 3). The differences are significant $(P=0.01)$. In contrast to fibrinogen, factors II, V, VII, and X where development was delayed in hypoxemic animals, factor VIII activity was increased in the hypoxemic animals throughout the early neonatal period as compared to controls ( $P=0.01$; Fig. 5). Factor IX activity also increased in hypoxemic animals throughout the 14 days after delivery exceeding control levels by the end of the 


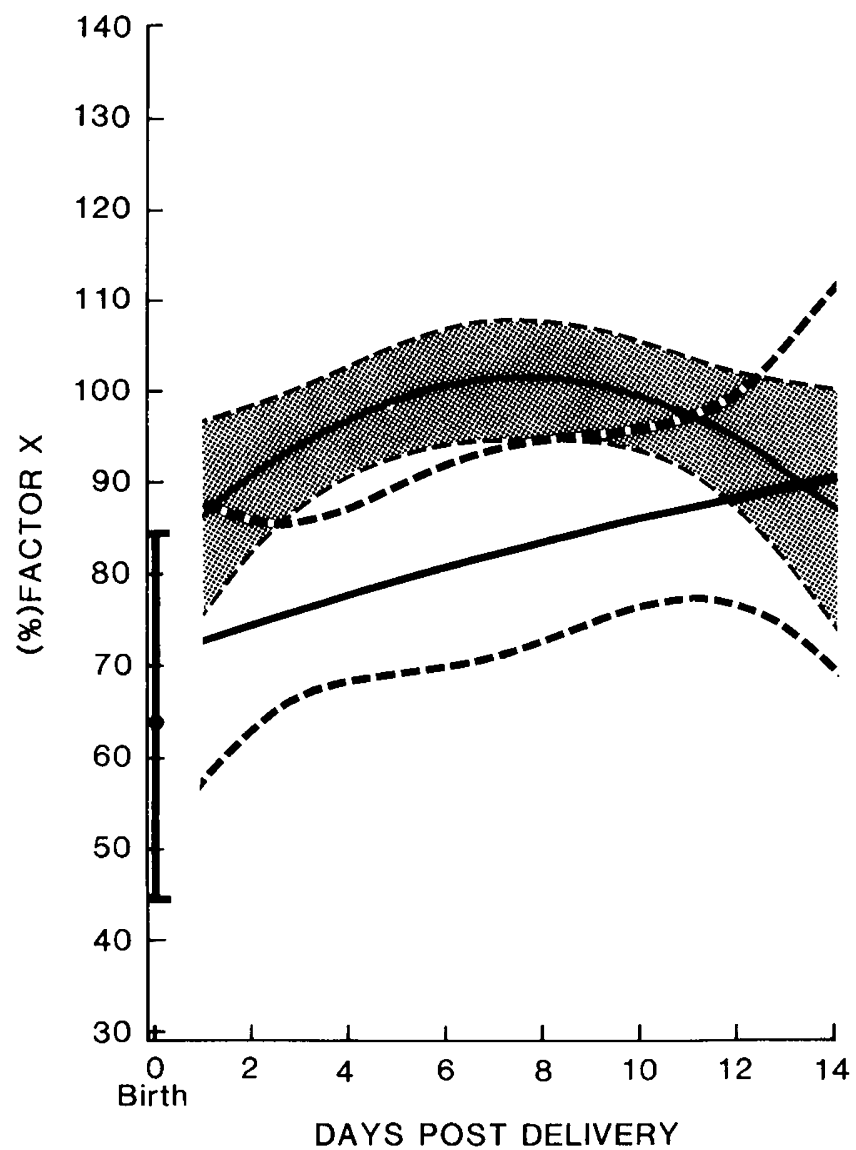

Fig. 7. Factor X. Mean \pm 1 S.D. of values on 14 control animals within $24 \mathrm{~h}$ of delivery indicated as a bar at birth. Thin lines and shaded area indicate regression curve and $95 \%$ confidence limits obtained on samples from 14 control animals during 14 days after birth. Heavy lines and open area indicate regression curve and $95 \%$ confidence limits obtained on samples from six hypoxemic animals during 14 days after birth. Groups are significantly different $(P=0.01)$.

second wk ( $P=0.01$; Fig. 6 ). The increased activities of factors VIII and IX suggest that the hypoxemic episode in some way accelerated the maturation of these factors.

The episode of hypoxemia in the near-term fetal lamb is complex and appears to result in impairment of development of some clotting factor activities (fibrinogen, factors II, V, VII, and X) or whereas it accelerates the development of others (factors VIII and IX).

As reported by Dam (7) human infants who suffered intrauterine asphyxia had exceptionally low prothrombin activities. The studies by Hathaway and Henderson (8) in newborn puppies surviving prolonged periods (18-24 hs) of systemic hypoxia demonstrated deficiences of both vitamin $\mathrm{K}$-dependent factors (II, VII, and X) and nonvitamin K-dependent factor, factor V. Vitamin $\mathrm{K}$, if administered to the bitch, protected her newborn puppies against the effects of hypoxemia in Hathaway's studies. In our studies, the fetus was exposed to $1 \mathrm{~h}$ of severe hypoxemia an average of 6 days before delivery. We also observed an impairment in the development of some of the liver dependent factors including fibrinogen, factors II, V, VII, and X during the first 14 days after delivery. We did not administer vitamin $K$ to the mothers of any of these animals so we cannot comment on the protective effects that vitamin $\mathrm{K}$ may have on the fetus exposed to hypoxemia.

In contrast to the impaired development of fibrinogen, factors II, V, VII, and X, both factors VIII and IX activities were increased in the hypoxemic group during the early neonatal period. Hathaway and Henderson (8) did not find any significant effects of hypoxemia on the activity of factor VIII in the newborn puppies in which it was measured and factor IX was not measured. Hathaway and co-workers (9) in another study of newborn human infants of high risk pregnant women, however, did find increased factor VIII activity in the cord blood of 13 infants with fetal distress (9). Similar to our findings in fetal lambs, Perlman and Dvilansky (22) observed increased factor VIII activity, low factor $\mathrm{V}$ activity, and fibrinogen in human newborns with gross placental infarction, a condition associated with fetal hypoxemia. Thomas (27) reporting on coagulation in low birth weight infants found better than normal coagulation in infants stressed as a result of maternal pre-eclampsia, toxemia, placental insufficency or antipartum hemorrhage. The values of specific factors were not presented and only fibrinogen concentration and a thrombotest was done on these infants.

Our studies suggest that fetal hypoxemia in the near-term fetus results in only minimal changes of coagulation factors during and immediately after the hypoxemic episode. Significant changes are, however, observed in the first 14 days after birth. These changes include an impairment in the development of fibrinogen, prothrombin, factors V, VII, and X and an enhancement of the activities of factors VIII and IX. There was no apparent effect on factors XI and XII and there was no suggestion of persistent disseminated intravascular coagulation.

The mechanisms for the differences observed during the early neonatal period in lambs exposed to hypoxemia near-term might be related to changes in protein syntheses and degradation; alterations in the specific activities of the proteins and/or variations in the levels of possible inhibitors of the activities of the proteins. It is unlikely that the differences are related to vitamin $\mathrm{K}$ because factor IX, a vitamin $\mathrm{K}$-dependent factor, is increased whereas

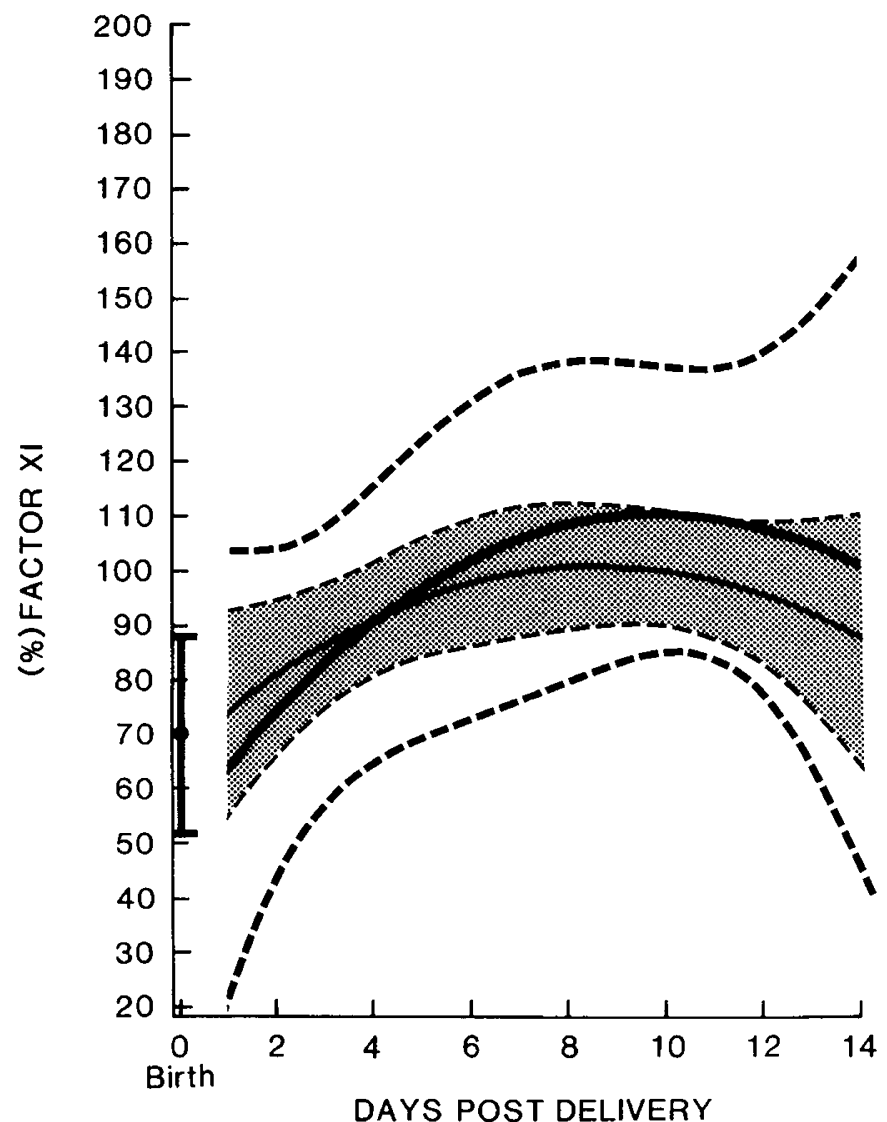

Fig. 8. Factor XI. Mean \pm 1 S.D. of values on 14 control animals within $24 \mathrm{~h}$ of delivery indicated as a bar at birth. Thin lines and shaded area indicate regression curve and $95 \%$ confidence limits obtained on samples from 14 control animals during 14 days after birth. Heavy lines and open area indicate regression curve and $95 \%$ confidence limits obtained on samples from six hypoxemic animals during 14 days after birth. Groups are significantly different $(P>0.05)$. 


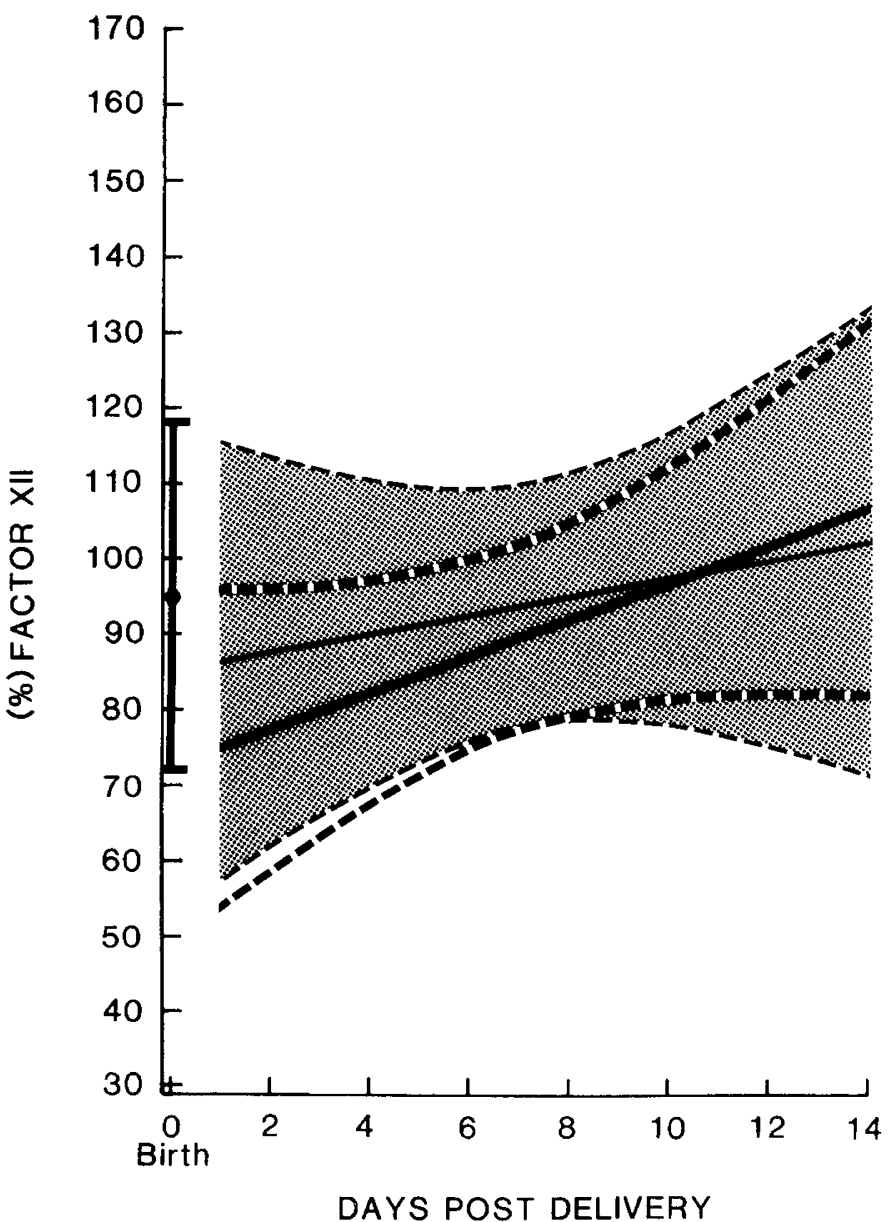

Fig. 9. Factor XII. Mean \pm I S.D. of values on four concurrent control animals within $24 \mathrm{~h}$ of delivery indicated as a bar at birth. Thin lines and shaded area indicate regression curve and $95 \%$ confidence limits obtained on samples from four control animals during 14 days after birth. Heavy lines and open areas indicate regression curve and $95 \%$ confidence limits obtained on samples from six hypoxemic animals during 14 days following birth $(P>0.05)$.

factors II, VII, and X also vitamin $\mathrm{K}$-dependent factors show impaired development. We have treated a newborn lamb with coumadin, a vitamin $\mathrm{K}$ antagonist, and demonstrated decreases in all vitamin $\mathrm{K}$-dependent factors including factor IX (11).

Fibrinogen and factor $\mathrm{V}$ show impaired development. Neither are vitamin $\mathrm{K}$ dependent factors. Though the mechanisms are unknown, the changes in the development of coagulation factor activities subsequent to fetal hypoxemia near-term could contribute to either neonatal thrombotic or hemorrhagic complications.

\section{REFERENCES AND NOTES}

1. Anderson, J. M., Brown, J. K., and Cockburn, F.: On the role of disseminated intravascular coagulation in the pathology of birth asphyxia. Develop. Med. Child. Neurol., 16: 581 (1974).

2. Appleyard, W. J. and Cottom, D. G.: Effect of asphyxia on thrombostest values in low birthweight infants. Arch. Dis. Child., 45: 705 (1970).

3. Brinkhous, K. M. and Read, M. S.: Preservation of platelet receptors for platelet aggregating factor/von Willebrand factor by air drying, freezing, or lyophilization: new stable platelet preparations for von Willebrand factor assays. Thromb. Res., 13: 591 (1978).

4. Chadd, M. A., Elwood, P. C., Gray, O. P., and Muxworthy, S. M.: Coagulation defects in hypoxic full term newborn infants. Brit. Med. J., 4: 516 (1971).

5. Chesselis, J. M. and Wigglesworth, J. S.: Coagulation studies in severe birth asphyxia. Arch. Dis. Child., 46: 253 (1971).

6. Clauss, V. A.: Gerinnungsphysiologische Schnellmethode zur Bestimmung des Fibrinogens. Acta. Haematol., 17: 237 (1957).

7. Dam, H., Dyggve, H., Larsen, H., and Plum, P.: The relation of vitamin $K$ deficiency to hemorrhagic disease of the newborn. Adv. in Pediatr., 5: 129 (1952).

8. Hathaway, W. E. and Henderson, B. J.: Effect of hypoxia on coagulation factors in newborn dogs. Biol. Neonat., 13: 26 (1968).

9. Hathaway, W. E., Mahasandana, C., and Makowski, E. L.: Cord blood coagulation studies in infants of high-risk pregnant women. Am. J. Obst. Gynecol., 121: 51 (1975).

10. Jennings, J. J. and Crowley, J.: The influence of mating management on fertility in ewes following progesterone-PMS treatment. Vet. Rec., 90: 495 (1972).

11. Kisker, unpublished data.

12. Kisker, C. T., Plummer, G., Taylor, B., and Rush, B.: A method for measuremen for measuring monomer with the use of an immune precipitate of fibrinogen. J. Lab. Clin. Med., 89: 653 (1977).

13. Kisker, C. T., Robillard, J. E., and Clarke, W. R.: Blood coagulation changes following hypoxemia. A fetal lamb model. Pediatr. Res., in press.

14. Kisker, C. T., Robillard, J. E., and Clarke, W. R.: Development of blood coagulation-a fetal lamb model. Pediatr. Res., 15: 1045 (1981).

15. Leff, B., Henriksen, R. A., and Owen, W. G.: Effect of oral contraceptive use on platelet prothrombin converting (platelet factor 3 ) activity. Thromb. Res., 15 : 631 (1979).

16. Markarian, M., Lindley, A., Jackson, J. J., and Bannon, A.: Coagulation factors in pregnant women and premature infants with and without respiratory distress syndrome. Thromb. Diath. Haemorrh., 17: 585 (1967).

17. Merskey, C., Lalezari, P., and Johnson, A. J.: A rapid simple sensitive method for measuring fibrinolytic split products in human serum. Proc. Soc. Exp. Biol. Med., 131: 871 (1969).

18. Muntean, W. and Muller, W. D.: Gerinnungsuntersuchungen aus Kapillarblut bei Neurgeborenen. Helv. Paediatr. Acta., 31: 149 (1976).

19. Neter, J. and Wasserman, W.: Applied linear statistical models. pp. 486-492 (Richard D. Irwin Inc., Homewood, IL, 1974).

20. Owen, C. A., Bowie, E. J., Didisheim, P., and Thompson, J. H.: Tests of hemostasis and blood coagulation. In: Charles A. Owen, E. J. Bowie, Paul Didisheim, John H. Thompson, Ed., Leo P. Cawley, Series Ed.: The Diagnosis of Bleeding Disorders. p. 105 (Little, Brown \& Co., Boston, MA, 1969).

21. Passon, P. G. and Peuler, J. D.: A simplified radiometric assay for plasma norepinephrine and epinephrine. Anal. Biochem., 51: 618 (1973).

22. Perlman, M. and Dvilansky, A.: Blood coagulation status of small-for-dates and postmature infants. Arch. Dis. Child., 50: 424 (1975).

23. Proctor, R. R. and Rapaport, S. I. The partial thromboplastin time with kaolin: A simple screening test for first stage plasma clotting factor deficiences. Am. J. Clin. Pathol., 36: 212 (1961).

24. Robillard, J. E., Matson, J., Sessions, C., and Smith, F. G.: Developmental aspects of renal tubular reabsorption of water in the lamb fetus. Pediatr. Res., 13: 1172 (1979).

25. Rogner, G., Maak, B., and Frenzel, J.: Das Verhalten der Gerinnungsfaktoren bei hypoxischen Neugeborenen unter der Puffertherapie. Z. Kinderheilkd., 104: 218 (1968).

26. Spirer, Z., Shalit, I., and Zakuth, V.: Decreased antihaemophilic globulin and leukocyte response to epinephrine in preterm infants. Arch. Dis. Child., 51: 231 (1976).

27. Thomas, D. B.: Prenatal stress, hyaline membrane disease, and coagulation factors in low birthweight babies. Aust. Paediatr. J., 11: 26 (1975)

28. Tocantins, L. M.: Estimation of prothrombin (one-stage method of Quick). In: L. M. Tocantins, and L. A. Kayal, Ed.: Blood Coagulation, Hemorrhage and Thrombosis: Methods of Study. p. 148 (Grune and Stratton, Inc., New York, 1964).

29. Von Creveld, A., Paulssen, M. M. P., and Teng, S. K.: Prothrombin and accelerator globulin in the plasma of newborns under normal and pathological conditions. Etudes Neonat., $1: 87$ (1952).

30. Requests for reprints should be addressed to: Dr. C. Thomas Kisker, University of Iowa Hospitals and Clinics, Department of Pediatrics, Iowa City, IA 52242.

31. This research was supported by the National Institute of Health and Research Grant R01 HD12574.

32. Received for publication September 18, 1981

33. Accepted for publication February 12, 1982. 